\title{
Endoscopic resection of early-stage SMAD4 juvenile polyposis does not prevent disease spreading in the stomach
}

To the best our knowledge, juvenile polyposis with a SMAD4 germline mutation is a rare disease [1,2], and its precise endoscopic aspect has been described in the colon [3] but not in the stomach. The natural history of this particular polyposis has not been well described.

We report a case of early-stage SMAD4 polyposis in a 25-year-old woman who was also receiving treatment for RenduOsler disease. It was an early-stage SMAD4 polyposis with a single large lesion ( $\mathbf{F i g . 1}$ ) surrounding the cardia. According to the endoscopic aspect in white-light imaging, the lesion was nodular (Paris classification Is). Using narrow-band imaging (Olympus, Tokyo, Japan), dual focus, and acetic acid dyeing, the mucosal pattern appeared regular with large pits consistent with hyperplasia. As the lesion had been detected at an early stage, we decided to attempt endoscopic submucosal dissection (ESD) to remove all of the polyp with margins in order to stop the evolution of the disease ( $\vee$ Video 1 ). En bloc resection was achieved and appeared to be endoscopically complete; the resected specimen measured $8 \times 3 \mathrm{~cm}$. Histology confirmed the hyperplastic nature of the polyp with free margins (focal contact in few points). During the follow-up period, the dissected area had a depressed aspect without recurrence at the scar site. However, the hyperplastic polyp recurred all around the previous resection site and spread all around the cardia ( $\triangleright$ Fig. 2 ).

In parallel, a second small juvenile polyp was present in the fundus and was described with blue-laser imaging and linked-color imaging. The lesion was small $(<5 \mathrm{~mm})$ and presented the same regular mucosal pattern with hyperplastic features ( $\triangleright$ Fig. 3, $\triangleright$ Fig. 4).

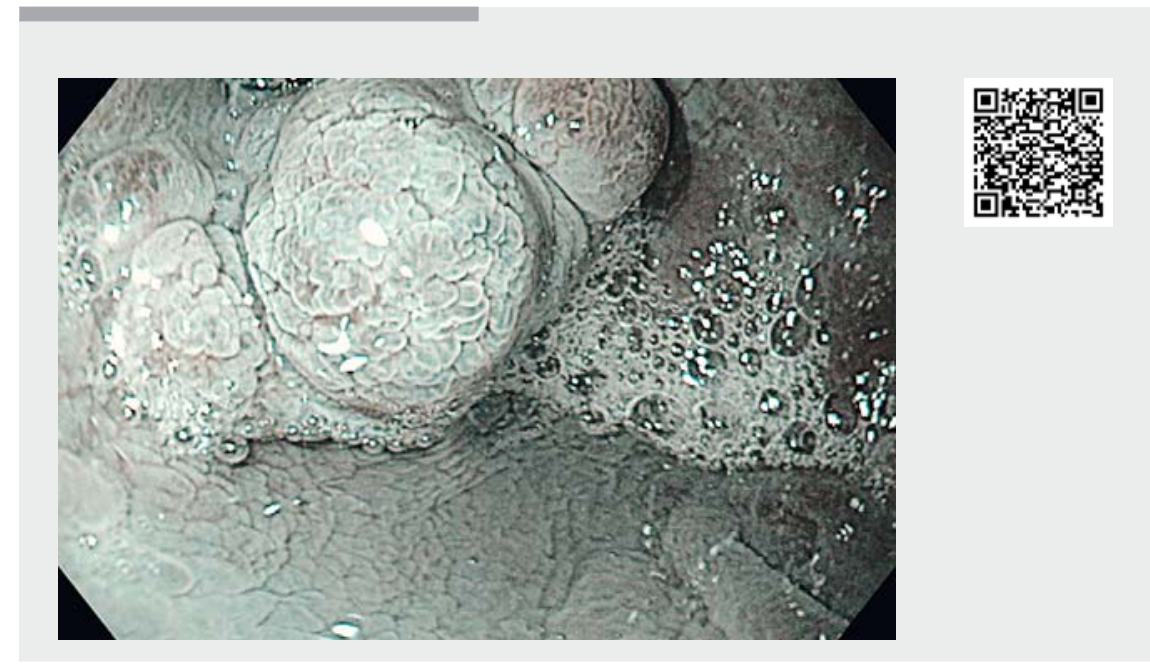

Video 1 SMAD4 juvenile polyposis aspect before and after endoscopic submucosal dissection of the main initial lesion.
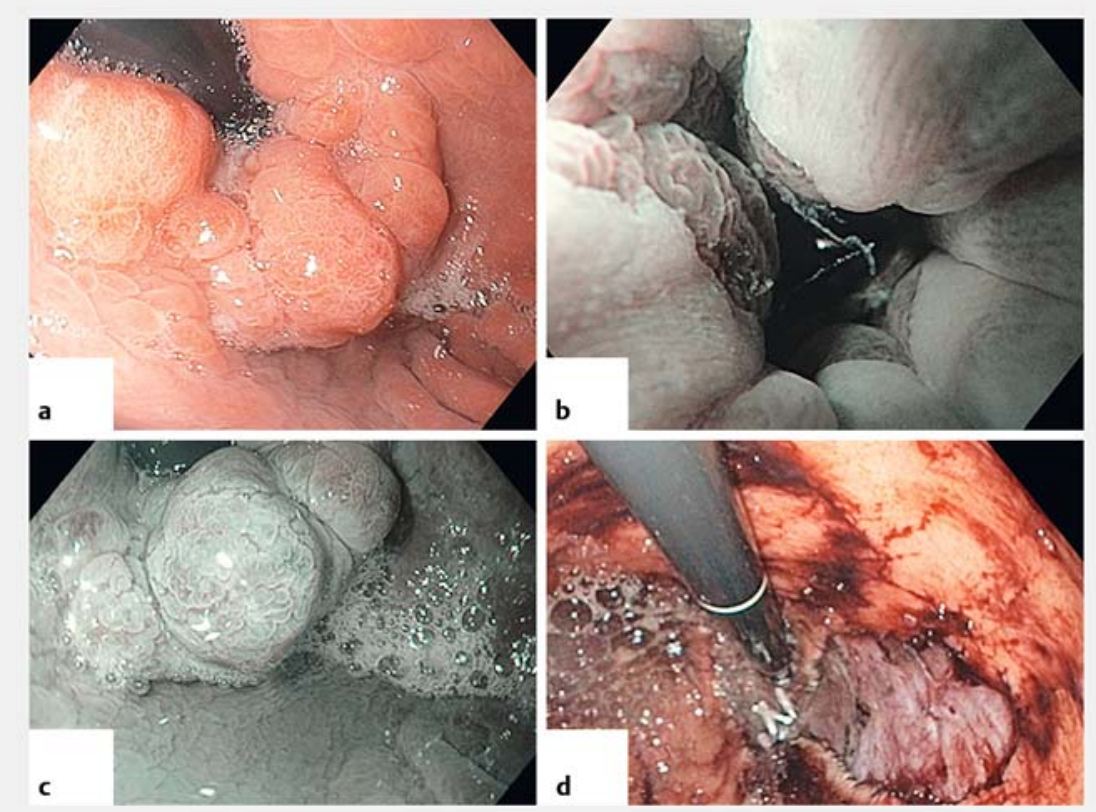

- Fig. 1 Endoscopic aspect of the initial lesion surrounding the cardia and of the resected area after endoscopic submucosal dissection (ESD). a White-light imaging. b Narrow-band imaging (NBI). c NBI and acetic acid. $\mathbf{d}$ The resection site after complete en bloc ESD. 

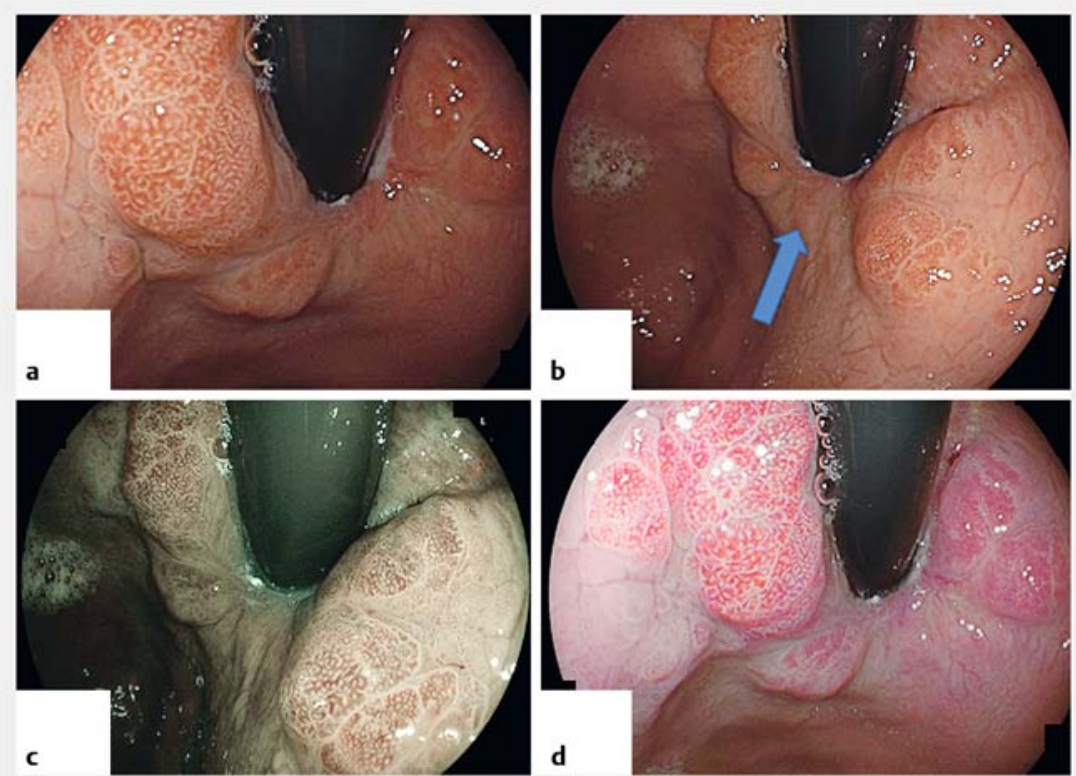

Fig. 2 Endoscopic aspect of the recurrence all around the site of the previous resection. a, b White-light endoscopy (arrow on the central scar). c Blue-laser imaging. d Linked-color imaging.
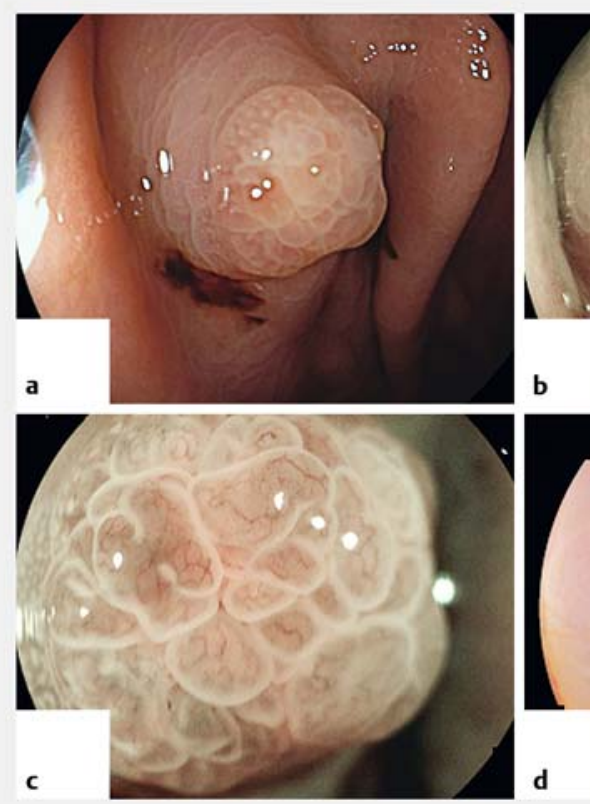

- Fig. 3 Aspect of a small gastric polyp with hyperplastic aspect. a White-light endoscopy. b, c Blue-laser imaging. d Linked-color imaging mode.
SMAD4 polyposis at an early stage seems to begin around the cardia but endoscopic resection, even when complete, does not prevent the lesion from spreading all around the cardia.

Endoscopy_UCTN_Code_CCL_1AB_2AD_3AB

Competing interests

None

The authors

Etienne Baldysiak ${ }^{1}$, Nicolas Benech ${ }^{1}$, Laura Calavas ${ }^{1}$, Jérôme Rivory ${ }^{1}$, Pierre-Marie Lavrut $^{2}$, Jean-Christophe Saurin ${ }^{1}$, Mathieu Pioche $^{1,3}$

1 Department of Endoscopy and Gastroenterology, Pavillon L, Edouard Herriot Hospital, Lyon, France

2 Digestive Pathology, Hospices Civils de Lyon, France

3 Inserm U1032 LabTau, Lyon, France

Corresponding author

\section{Mathieu Pioche, MD}

Endoscopy Unit - Digestive Disease department, Pavillon L - Edouard Herriot Hospital, 69437 Lyon Cedex, France Fax: +33-4-72110147 mathieu.pioche@chu-lyon.fr

\section{References}

[1] Chung AD, Mortelé KJ. Combined juvenile polyposis syndrome and hereditary hemorrhagic telangiectasia (JPS/HHT) with MRI and endoscopic correlation. Clin Imaging 2018; 54: $37-39$

[2] lyer NK, Burke CA, Leach BH et al. SMAD4 mutation and the combined syndrome of juvenile polyposis syndrome and hereditary haemorrhagic telangiectasia. Thorax 2010; 65: $745-746$

[3] Takeda K, Kudo S-E, Mori Y et al. Magnifying chromoendoscopic and endocytoscopic findings of juvenile polyps in the colon and rectum. Oncol Lett 2016; 11: $237-242$ 


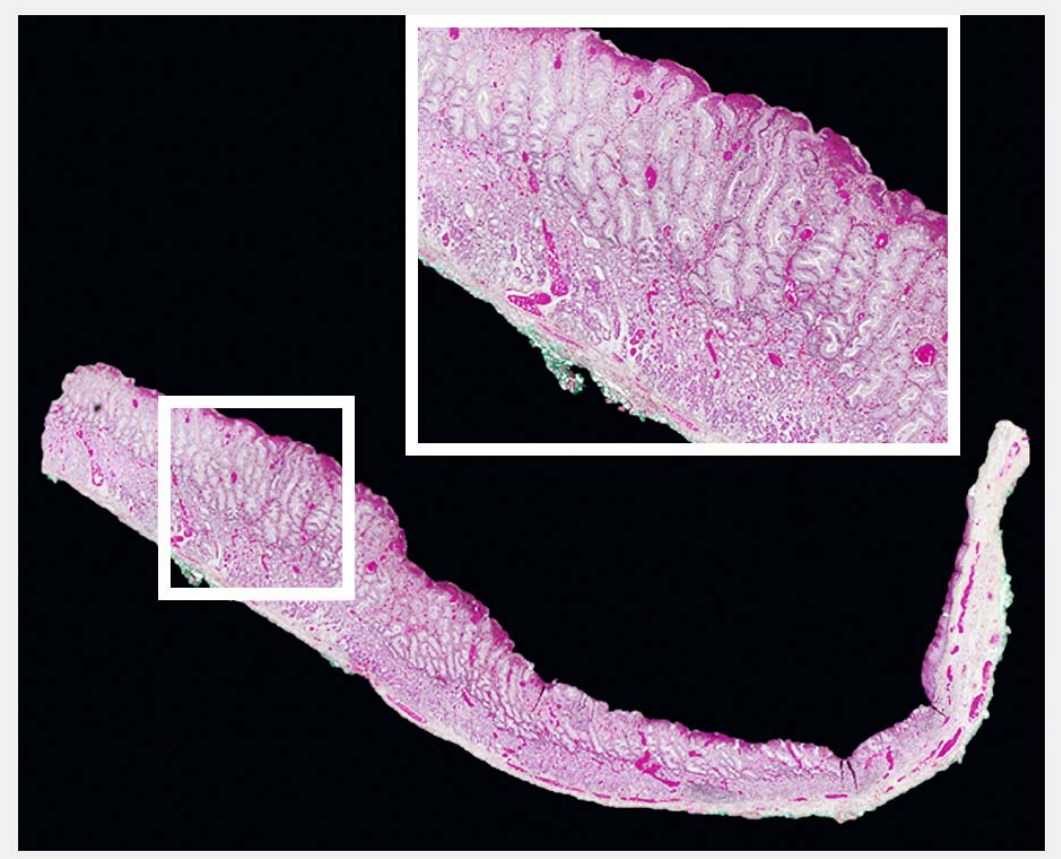

- Fig. 4 Histology of the lesion with hyperplastic features.

\section{Bibliography}

DOI https://doi.org/10.1055/a-0978-6734

Published online: 9.8.2019

Endoscopy 2020; 52: E17-E19

(c) Georg Thieme Verlag KG

Stuttgart · New York

ISSN 0013-726X

\section{ENDOSCOPY E-VIDEOS}

https://eref.thieme.de/e-videos

回血 Endoscopy E-Videos is a free

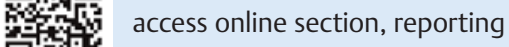
回船: on interesting cases and new techniques in gastroenterological endoscopy. All papers include a high quality video and all contributions are freely accessible online.

This section has its own submission website at

https://mc.manuscriptcentral.com/e-videos 